\title{
RELAÇÃO ENTRE O LIMITE DE PLASTICIDADE E A UMIDADE ÓTIMA DE COMPACTAÇÃO DE UM LATOSSOLO VERMELHO-ESCURO EM DIFERENTES CONDIÇÕES DE USO
}

\author{
Diego Monteiro Dias ${ }^{1}$, Gracielly Ribeiro de Alcântara² ${ }^{2}$ Elton Fialho dos Reis ${ }^{3}$
}

\section{RESUMO}

\begin{abstract}
A correlação entre o limite de plasticidade e a umidade ótima de compactação, tem grande aplicação em avaliações de solo para diferentes usos, como a interação máquina-solo. Este trabalho teve como objetivo determinar a relação existente entre o limite de plasticidade e a umidade ótima de compactação de um Latossolo Vermelho-Escuro em diferentes condições de uso. $\mathrm{O}$ experimento foi desenvolvido na área experimental da Agência Rural, localizada no município de Anápolis e no Laboratório de Mecânica dos Solos da Unidade Universitária de Ciências Exatas e Tecnológicas da Universidade Estadual de Goiás. O delineamento experimental instalado foi inteiramente casualizado em esquema fatorial $4 \times 3$, sendo quatro tipos de uso do solo (solo em plantio direto com milho, solo em sistema convencional com soja, cultivo de frutíferas e pastagens degradadas a três profundidades diferentes $(0 \mathrm{a} 10 \mathrm{~cm} ; 10$ a $20 \mathrm{~cm}$ e 20 a $30 \mathrm{~cm}$ ), com três repetições. Os resultados indicaram que a menor umidade ótima de compactação encontrada foi para o solo cultivado com milho. Os valores de limite de plasticidade foram superiores a umidade ótima de compactação para todos os tipos de uso do solo. As operações, com máquinas agrícolas, próximas ao limite superior do estado friável causam compactação em todos os tipos de uso do solo.
\end{abstract}

Palavras-chave: compactação do solo, degradação do solo, solo argiloso.

\section{ABSTRACT \\ RELATIONSHIP BETWEEN PLASTICITY LIMIT AND THE OPTIMUM MOISTURE FOR COMPACTION OF A DARK-RED LATOSOL (OXISOL) IN DIFFERENT CONDITIONS OF USE}

The correlation between plasticity limit and the optimum moisture for compaction is highly useful to assess soil for different uses such as machine-soil interaction. This work was done to determine the relationship between the plasticity limit and the compacting optimal moisture of a dark-red latosol (oxisol) in different conditions of use. The experiment was done in an experimental field of the Agência Rural, located in the city of Anápolis and the Laboratory of Soil Mechanics of the University and the Exact and Technological Sciences unit of the Universidade Estadual of Goiás. The experiment was installed with three replications in the completely randomized design, in $4 \times 3$ factorial, (four types of soil use (soil under no-tillage corn, soil under conventional tillage with soybean, fruit orchard and a degraded pasture) and three soil depths (0 to $10 \mathrm{~cm}, 10$ to $20 \mathrm{~cm}$ and 20 to $30 \mathrm{~cm})$.. The results showed that the lowest compaction optimal moisture was in the corn cultivated soil. The values of plastic limit were higher than the compaction optimal moisture in all types of soil use. The use of agricultural machines close to upper limit of the friable state causes compaction in all types of soil use.

Keywords: compacting of the soil, soil degradation, and argillaceous soil.

\section{Recebido para publicação em 10/02/2010. Aprovado em 20/10/2011.}

1- Engenheiro Agrícola, Universidade Estadual de Goiás - UEG, Anápolis, GO.

2- Engenheira Agrícola e Doutoranda em Mecanização Agrícola, Universidade Federal de Viçosa - DEA/UFV, cyalcantara@gmail.com

3- Engenheiro Agrícola, Professor Adjunto da Universidade Estadual de Goiás - UEG, Anápolis, GO, fialhoreis@ueg.br 


\section{INTRODUÇ̃̃O}

A principal exigência para o bom desenvolvimento de uma cultura é um solo com ótimas condições físicas, dentre elas: distribuição adequada de espaços porosos, otimizando a disponibilidade de água e trocas gasosas e proporcionando o desenvolvimento das raízes sem impedimentos mecânicos, e temperaturas adequadas. As culturas exercem influência considerável sobre os espaços porosos na camada de aradura. O cultivo tende a diminuir os espaços de poros para valores aquém dos correspondentes a solos virgens ou não cultivados. Essa redução vem, em geral, associada com a diminuição do montante de matéria orgânica e consequente abaixamento da granulação. Tem-se constatado que o cultivo ocasiona diminuição nos espaços porosos no subsolo, embora em menor extensão (KIEHL, 1979). Entretanto, as atividades realizadas na produção agrícola, principalmente em umidades elevadas, causam modificações na estrutura do solo, provocando restrições ao desenvolvimento do sistema radicular, por intermédio da compactação.

A consistência do solo é uma das características mais importantes para a engenharia, pois determina o comportamento do solo ante determinadas tensões e deformações; igualmente, o grau de consistência do solo exerce considerável influência sobre o regime de água no mesmo, afetando a condutividade hidráulica e permitindo fazerem-se inferências sobre a curva de umidade; além do mais, é determinante na resistência do solo à penetração e na compactação e seu conhecimento possibilita a determinação do momento adequado do uso de técnicas que favoreçam um bom manejo do solo, propiciando melhor conservação do mesmo, além de diminuir a demanda energética nas operações mecanizadas (SOUZA et al., 2000).

A intensa mecanização aplicada aos solos da Região dos cerrados tem comprometido suas propriedades físicas, tais como: a permeabilidade à água e ao ar, água disponível, a densidade do solo e a erodibilidade (CANILLAS; SALOKHE, 2002; OLIVEIRA et al., 2003). O uso de máquinas agrícolas nas várias etapas do processo de produção em condições inadequadas de umidade tem sido o principal responsável por acarretar a degradação da estrutura do solo, diminuindo seu potencial produtivo (DIAS JUNIOR; PIERCE, 1996).

Quando um solo não saturado é submetido à determinada pressão, ocasionando redução de volume com consequente aumento de densidade, ocorre o processo de compactação do solo (GUPTA; ALLMARAS, 1987). A compactação do solo modifica a quantidade e a distribuição dos tamanhos de poros, alterando a quantidade e o fluxo de água no solo, o que altera a disponibilidade de água para as plantas, podendo apresentar efeitos benéficos ou adversos. Um dos principais problemas relacionados à compactação reside na realização de operações agrícolas com umidade inadequada para tráfego de máquinas. Esta situação se acentua nas áreas irrigadas, posto que a umidade do solo permanece frequentemente na capacidade de campo, quando o solo apresenta condições para sofrer máxima compactação.

Uma alternativa para avaliar a suscetibilidade do solo à compactação é o ensaio de Proctor Normal. Esse se baseia no fato de que a densidade na qual um solo é compactado, sob determinada energia de compactação, depende da umidade do solo no momento da compactação (PROCTOR, 1933). Por intermédio deste ensaio se determina o ponto ótimo para compactação do solo, ou seja, a umidade crítica em que não devemos trafegar com máquinas agrícolas ou realizar pastoreio na lavoura.

Em solos agrícolas, a pressão exercida na superfície do solo pelo tráfego de máquinas nas operações de preparo aumenta normalmente a densidade do solo e diminui a porosidade total, em especial a macroporosidade (TSEGAYE; HILL, 1998). Essa degradação na estrutura é agravada quando as operações de preparo de solo e tráfego de máquinas nas lavouras são realizadas em solos com consistência plástica, associadas a pressões superiores à pressão de pré-consolidação (FIGUEIREDO et al., 2000; SILVA et al., 2000; SILVA et al., 2003).

Caputo (1988) mostrou que o comportamento plástico dos materiais fundamenta-se nas características tensão-deformação. Assim, um 
corpo metálico recupera toda a sua forma original quando cessa o esforço de compressão, enquanto um corpo plástico se deforma para qualquer tensão aplicada. Entretanto, esses conceitos não são absolutos e dependem da intensidade das forças aplicadas, bem como do grau de precisão das observações efetuadas.

Atterberg (1911) identificou que um solo poderá apresentar-se, quando o teor de umidade aproximar-se da capacidade de campo, menos aderente e mais plástico, portanto, sujeito a mudança permanente de sua forma, pela ação de uma força aplicada.

Entre outros fatores, é fato que o comportamento do solo varia em função da umidade. No entanto, existem alguns limites estabelecidos para caracterizar, de maneira simples e rápida, o comportamento de um solo quanto à sua plasticidade, os quais se constituem em determinações rotineiras nos laboratórios de física e mecânica dos solos. Dentre esses limites, os dois mais tradicionais foram estabelecidos por Atterberg (1911) (limites de Atterberg), sendo denominados de limite de liquidez (LL) e limite de plasticidade (LP). A diferença entre esses dois limites é conhecida como índice de plasticidade (IP).

Dias Junior e Estanislau (1999) comentam que após atingir a umidade ótima de compactação, à medida que a umidade aumenta, a densidade do solo diminui devido à baixa compressibilidade da água que ocupa a maioria dos poros para condições próximas da saturação. Kiehl (1979) afirmou que o preparo do solo em condições corretas de umidade promove a agregação, melhorando a estruturação e, por essas razões, aumenta a porosidade.

A correlação entre o limite de plasticidade e a umidade ótima de compactação tem grande aplicação dentro da ciência do solo em avaliações de solo para uso em fundações, construções de estradas e interação máquina-solo. $\mathrm{O}$ presente trabalho tem como objetivo determinar a relação existente entre o limite de plasticidade e a umidade ótima de compactação de um Latossolo VermelhoEscuro em diferentes condições de uso.

\section{MATERIAL E MÉTODOS}

O trabalho foi desenvolvido na área experimental da Agência Rural, localizada no município de Anápolis, GO, com altitude de $1017 \mathrm{~m}$, longitude $48^{\circ} 18^{\prime} 23^{\prime \prime} \mathrm{W}$ e latitude $16^{\circ} 19^{\prime} 44^{\prime \prime} \mathrm{S}$. A área apresenta Latossolo Vermelho-Escuro Eutrófico com textura argilosa e topografia com declividade média variando de 1 a $5 \%$, além de algumas características climáticas como a precipitação média anual de $365,10 \mathrm{~mm}$; a umidade relativa anual média do ar é de 82 a $85 \%$ e a temperatura média anual de $27,4{ }^{\circ} \mathrm{C}$ (INPE, 2011).

$\mathrm{O}$ experimento foi instalado em esquema fatorial $4 \times 3$, sendo quatro tipos de uso do solo (solo em plantio direto com milho, sistema convencional com soja, cultivo de frutíferas e pastagens degradadas) a três profundidades diferentes ( 0 a $10 \mathrm{~cm} ; 10$ a $20 \mathrm{~cm}$ e 20 a $30 \mathrm{~cm}$ ). O delineamento foi inteiramente casualizado, com três repetições.

As amostras foram extraídas em pontos com áreas de aproximadamente $1 \mathrm{~m}^{2}$, retirando toda a cobertura superficial. As profundidades foram medidas utilizando-se uma régua graduada em centímetros. Fez-se a caracterização de alguns dos atributos físicos do solo, como, densidade de partículas, densidade do solo, porosidade total, massa específica seca e análise textural, de acordo com a metodologia proposta pela EMBRAPA (1997). Estes atributos podem ser visualizados nas Quadros 1 e 2.

Quadro 1. Características texturais médias para os diferentes tipos de uso de solo

\begin{tabular}{ccccccc}
\hline & \multicolumn{5}{c}{ Classificação Textural } \\
\cline { 2 - 6 } Culturas & $\begin{array}{c}\text { Areia grossa } \\
\left(\mathrm{g} \mathrm{kg}^{-1}\right)\end{array}$ & $\begin{array}{c}\text { Areia fina } \\
\left(\mathrm{g} \mathrm{kg}^{-1}\right)\end{array}$ & $\begin{array}{c}\text { Areia total } \\
\left(\mathrm{g} \mathrm{kg}^{-1}\right)\end{array}$ & $\begin{array}{c}\text { Argila } \\
\left(\mathrm{g} \mathrm{kg}^{-1}\right)\end{array}$ & $\begin{array}{c}\text { Silte } \\
\left(\mathrm{g} \mathrm{kg}^{-1}\right)\end{array}$ & Textura \\
Soja & 70 & 400 & 470 & 440 & 90 & Areno-Argiliso \\
Frutífera & 110 & 380 & 490 & 430 & 80 & Areno-Argiliso \\
Milho & 110 & 450 & 560 & 400 & 40 & Areno-Argiliso \\
Pastagem & 150 & 390 & 540 & 400 & 60 & Areno-Argiliso \\
\hline
\end{tabular}


Quadro 2. Características físicas para os diferentes tipos de uso dos solos

\begin{tabular}{ccccc}
\hline \multirow{2}{*}{ Solos } & \multicolumn{4}{c}{ Características Físicas } \\
\cline { 2 - 5 } & $\begin{array}{c}\text { Densidade de partícula } \\
\left(\mathrm{g} \mathrm{cm}^{-3}\right)\end{array}$ & $\begin{array}{c}\text { Densidade do solo } \\
\left(\mathrm{g} \mathrm{cm}^{-3}\right)\end{array}$ & $\begin{array}{c}\text { Porosidade } \\
\text { total } \%\end{array}$ & $\begin{array}{c}\text { Massa Específica } \\
\text { Seca }\left(\mathrm{g} \mathrm{cm}^{-3}\right)\end{array}$ \\
Soja & 2,587 & 1,648 & 36,30 & 1,39 \\
Frutífera & 2,544 & 1,282 & 49,61 & 1,36 \\
Milho & 2,578 & 1,436 & 44,30 & 1,39 \\
Pastagem & 2,584 & 1,520 & 41,18 & 1,44 \\
\hline
\end{tabular}

Para a determinação do limite de liquidez e o limite de plasticidade foi utilizado o procedimento descrito pela EMBRAPA (1997), com 5 repetições para cada processo. $O$ índice de plasticidade corresponde à faixa de valores de umidade do solo, na qual ele se comporta de maneira plástica, ou seja, é a quantidade máxima de água que pode ser adicionada a partir do limite de plasticidade. O índice de plasticidade foi determinado pela Equação 1.

$\mathrm{IP}=\mathrm{LL}-\mathrm{LP}$

em que

IP = Índice de plasticidade;

$\mathrm{LL}=$ Limite de liquidez; e

LP $=$ Limite de plasticidade.

Para realização do ensaio de Proctor normal, foi utilizada a metodologia descrita por Vargas (1977). Após a realização de cada ensaio foram retiradas amostras, como descrito em cada método, para a determinação do teor de umidade pelo método padrão da estufa, a $105^{\circ} \mathrm{C}$, por 24 horas.

A análise dos resultados foi baseada na análise de variância e, quando significativos, foram submetidas ao teste de Tukey para comparação das médias ao nível de significância de 5\%, utilizando o programa SAEG 9.1 (SAEG, 2007).

\section{RESULTADOS E DISCUSSÕES}

Os resultados da análise indicam que: $\mathrm{O}$ tipo de uso do solo afetou significativamente o limite de liquidez, limite de plasticidade, índice de plasticidade e a umidade ótima de compactação (Wot); e a profundidade afetou somente os limites de liquidez e o índice de plasticidade (Quadro 3). A interação entre o tipo de uso do solo e a profundidade afetou, significativamente, o limite de plasticidade e o índice de plasticidade. Esta diferença evidenciada, possivelmente ocorreu devido aos solos serem utilizados por diferentes sistemas de plantio e culturas.

Os valores médios para o limite de liquidez nos diferentes tipos de uso do solo podem ser vistos no Quadro 4. O solo cultivado com milho apresentaram as menores médias de limite de liquidez. No entanto, as frutíferas e o solo cultivado com soja apresentaram os maiores valores de limite de liquidez, que segundo Sewell e Mote (1969), isso pode ocorrer devido o solo apresentar maior permeabilidade.

As médias do limite de liquidez obtidas nas diferentes profundidades dos solos estudadas podem ser visualizadas no Quadro 5. O maior valor de limite de liquidez foi encontrado na maior profundidade, sendo que nas menores profundidades não houve diferença significativa. Mostrando que nas camadas superficiais houve menor permeabilidade (SEWELL; MOTE, 1969) e possivelmente compactação ou adensamento superficial. Tal fato pode ter se dado em decorrência da utilização do solo.

Os resultados do limite de plasticidade mostram que o solo cultivado com frutíferas obteve a maior média, não diferindo dos solos usados para a cultura de soja e pastagem, sendo que, o solo com pastagem também não diferiu do solo usado para o cultivo de milho, quando fixada a profundidade de 0 a $10 \mathrm{~cm}$ (Quadro 6). Para a profundidade entre 10 e $20 \mathrm{~cm}$, o solo com frutífera também obteve a maior média, 
com $31,42 \%$, não diferindo do solo com plantio de soja, mas diferiu dos demais tipos de uso do solo. Para esta profundidade também não houve diferença entre os solos com plantio de milho e pastagem. Já para a profundidade entre 20 e 30 $\mathrm{cm}$, o único solo que diferiu dos demais solos foi o com cultivo de frutífera, que apresentou maior valor de LP.

Estudos feitos por Nettleton e Brasher (1983) e Smith et al. (1985) citados por SILVA et al. (2006), enfatizaram que o aumento da matéria orgânica tende a aumentar a área superficial específica do solo, com o consequente aumento de retenção de água, levando o solo a ter maiores valores de limite de plasticidade. Isto provavelmente pode ter ocorrido para o solo cultivado com frutífera, por apresentar maior quantidade de matéria orgânica e melhor estrutura. Os valores do limite de plasticidade quando se variam a profundidade e fixam-se o tipo de uso de solo (Quadro 6), mostram que para os solos cultivados com milho e frutífera não houve diferença significativa, já para pastagem a profundidade de 10 a $20 \mathrm{~cm}$, apresentou menor valor.

Para os valores médios dos índices de plasticidade nas diferentes profundidades e tipos de uso do solo, verifica-se que o solo cultivado com milho foi o que obteve a menor média diferindo de todos os outros tipos de uso do solo, quando se fixam a profundidade de 0 a $10 \mathrm{~cm}$. Na profundidade entre 10 e $20 \mathrm{~cm}$, o solo cultivado com pastagem foi o que obteve a maior média, que não diferiu do solo cultivado com milho, porém, diferiu dos demais tipos de uso do solo. Para esta profundidade também não houve diferença quando comparado aos solos cultivados com frutífera e milho.

Quadro 3. Resumo do quadro geral de análise de variância da variável tipo de uso do solo e profundidades para o limite de liquidez (LL), limite de plasticidade (LP), índice de plasticidade e teor de água ótima de compactação (Wot)

\begin{tabular}{cccccc}
\hline & & \multicolumn{4}{c}{ Quadrado Médio } \\
\cline { 3 - 6 } FV & GL & LL & LP & IP & Wot \\
\cline { 3 - 6 } Solo & 3 & $82,11012^{*}$ & $53,10729^{*}$ & $8,036756^{*}$ & $19,12963^{*}$ \\
Profundidade & 2 & $15,16314^{*}$ & 0,390641 & $20,00708^{*}$ & 0,506944 \\
Sol x Prof & 6 & 1,752062 & $6,305264^{*}$ & $8,280876^{*}$ & 2,831019 \\
RESíD & 24 & 1,485682 & 0,8482705 & 1,209939 & 3,5 \\
\hline Média & & 35,54 & 27,27 & 8,26 & 24,44 \\
CV (\%) & & 3,43 & 3,38 & 13,31 & 8,40 \\
\hline
\end{tabular}

* Significativo a $5 \%$ de probabilidade, pelo teste $\mathrm{F}$.

Quadro 4. Médias obtidas para o limite de liquidez para os diferentes tipos de uso do solo

\begin{tabular}{cc}
\hline Solo & Média do LL \\
\hline Frutífera & $38,65 \mathrm{~A}$ \\
Soja & $36,74 \mathrm{AB}$ \\
Pastagem & $35,23 \mathrm{~B}$ \\
Milho & $31,52 \mathrm{C}$ \\
\hline
\end{tabular}

Médias seguidas pelas mesmas letras não diferem entre si, a 5\% de probabilidade, pelo Teste de Tukey.

Quadro 5. Médias do limite de liquidez obtidos nas diferentes profundidades dos solos

\begin{tabular}{cc}
\hline Profundidade & Médias \\
\hline $20-30$ & $36,82 \mathrm{~A}$ \\
$10-20$ & $35,09 \mathrm{~B}$ \\
$0-10$ & $34,70 \mathrm{~B}$ \\
\hline
\end{tabular}

Médias seguidas pelas mesmas letras não diferem entre si, a 5\% de probabilidade, pelo Teste de Tukey. 
Ao se fixarem, o tipo de uso do solo e variando a profundidade, tem-se que na cultura da soja a profundidade de 0 a $10 \mathrm{~cm}$ diferiu das demais profundidades. Já nas demais profundidades, não diferiram significativamente entre si. Para os solos com cultura de milho e frutífera, o índice de plasticidade não demonstrou diferença entre as profundidades. Já para a cultura de pastagem nas profundidades de 0 a $10 \mathrm{~cm}$ e $10 \mathrm{a}$ $20 \mathrm{~cm}$, apresentaram-se iguais estatisticamente, mas diferenciaram da profundidade de 20 a 30 $\mathrm{cm}$. Isso pode ter sido devido à profundidade do sistema radicular das culturas.

Com relação aos valores médios da umidade ótima de compactação para os diferentes tipos de uso de solos (Quadro 8), constata-se que o solo usado para frutífera obteve a maior média, sendo iguais estatisticamente aos solos utilizados para o cultivo de soja e pastagem. $\mathrm{O}$ solo cultivado com milho apresentou a menor média para a umidade ótima e compactação. A redução da matéria orgânica nos solos cultivados, no entanto, pode reduzir o limite de plasticidade e a faixa de friabilidade, refletindo no aumento da compactação. O solo mais susceptível a compactação é o solo em uso com a cultura do milho, pois apresenta o menor valor de umidade ótima de compactação. Para este tipo de uso de solo, deve-se verificar com mais cuidado o tipo de pneu e carga aplicada pelo rodado das máquinas, pois ele apresenta uma menor faixa de umidade ideal para trabalho mecânico.

A susceptibilidade do solo à compactação é grande, quando próximo ao limite de plasticidade, devido a sua baixa resistência à compressão e consequentemente baixa capacidade de suporte de carga (DIAS JUNIOR ; PIERCE, 1996), ocorrendo, no caso estudado, a compactação do solo. Para se estudar a compactação do solo, o ensaio de "Proctor normal" tem sido utilizado (THOMAS et al., 1996; FIGUEIREDO et al., 2000), uma vez que determina o teor de água no qual o solo atinge a compactação máxima. Neste ensaio, para uma mesma energia de compactação, a densidade do solo depende de sua umidade no momento da compactação (CAPUTO, 1994).

Quadro 6. Médias do limite de plasticidade para a interação entre tipos de uso do solo e profundidade obtidos nos diferentes tratamentos

\begin{tabular}{ccccc}
\hline Profundidade & \multicolumn{4}{c}{ Solo } \\
\cline { 2 - 5 }$(\mathrm{cm})$ & Soja & Milho & Pastagem & Frutífera \\
\hline $0-10$ & $27,61 \mathrm{ABab}$ & $25,83 \mathrm{Ba}$ & $27,04 \mathrm{ABa}$ & $29,36 \mathrm{Aa}$ \\
$10-20$ & $29,45 \mathrm{Aa}$ & $23,52 \mathrm{Ba}$ & $24,64 \mathrm{Bb}$ & $31,42 \mathrm{Aa}$ \\
$20-30$ & $26,65 \mathrm{Bb}$ & $24,5 \mathrm{Ba}$ & $27,10 \mathrm{Ba}$ & $30,14 \mathrm{Aa}$ \\
\hline Média & 27,9 & 24,62 & 26,26 & 30,31 \\
\hline
\end{tabular}

Médias seguidas pelas mesmas letras maiúsculas na horizontal e minúscula na vertical não diferem entre si, a 5\% de probabilidade, pelo Teste de Tukey.

Quadro 7. Médias do índice de plasticidade para a interação entre tipos de uso do solo e profundidade nos diferentes tratamentos

\begin{tabular}{ccccc}
\hline \multirow{2}{*}{ Profundidade $(\mathrm{cm})$} & \multicolumn{4}{c}{ Solo } \\
\cline { 2 - 5 } & Soja & Milho & Pastagem & Frutífera \\
\hline $0-10$ & $7,64 \mathrm{Aa}$ & $5,61 \mathrm{Ba}$ & $6,79 \mathrm{Aa}$ & $8,94 \mathrm{Aa}$ \\
$10-20$ & $6,71 \mathrm{Bb}$ & $7,60 \mathrm{Aa}$ & $10,13 \mathrm{Aa}$ & $6,88 \mathrm{Ba}$ \\
$20-30$ & $12,16 \mathrm{Ab}$ & $7,51 \mathrm{Ba}$ & $9,99 \mathrm{Ab}$ & $9,21 \mathrm{Aa}$ \\
\hline Média & 8,84 & 6,91 & 8,97 & 8,34 \\
\hline
\end{tabular}

Médias seguidas pelas mesmas letras maiúsculas na horizontal e minúscula na vertical não diferem entre si, a 1\% de probabilidade, pelo Teste de Tukey. 
Quadro 8. Médias do teor de água ótimo de compactação para os diferentes tipos de uso do solo

\begin{tabular}{cc}
\hline Solo & Teor de água (\%) \\
\hline Frutífera & $25,72 \mathrm{~A}$ \\
Soja & $25,67 \mathrm{~A}$ \\
Pastagem & $23,44 \mathrm{AB}$ \\
Milho & $22,94 \mathrm{~B}$ \\
\hline
\end{tabular}

Médias seguidas pelas mesmas letras não diferem entre si, a 1\% de probabilidade, pelo Teste de Tukey.

Os valores do teor de água ótimo de compactação estão abaixo dos valores de limite de plasticidade (Quadros 6 e 8). O solo cultivado com frutífera apresentou maior valor de umidade ótima de compactação, não diferindo dos cultivados com soja e pastagem, isto ocorre possivelmente devido a maior presença de matéria orgânica, ocasionado pelos restos culturais da produção. Dias Júnior e Estanislau (1999) e Barzegar et al. (2000) notaram que as alterações na matéria orgânica do solo, devido aos diferentes sistemas de manejo, podem causar alterações nos parâmetros da curva de compactação do solo.

\section{CONCLUSÕES}

- Os valores do limite de plasticidade foram superiores aos valores de umidade ótima de compactação para todos os tipos de uso do solo;

- As operações com máquinas agrícolas, próximas ao limite superior do estado friável, causam compactação em todos os tipos de uso do solo;

- Os menores valores de limite de liquidez foram encontrados nas camadas superficiais (0 a 10 e 10 a $20 \mathrm{~cm})$;

- O solo cultivado com milho em sistema de plantio direto obteve o menor limite de liquidez e a menor umidade ótima de compactação; e

- É necessária bastante atenção ao tipo de utilização do solo, na forma de manejo, nos rodados das máquinas e na umidade do solo de trabalho, posto que podem degradar o solo, e o desenvolvimento radicular devido à sua compactação.

\section{BIBLIOGRAFIA}

ATTERBERG, A. Die Plastizität der Tone. Internationale Mitteilungen für Bodenkunde, Band I, Heft, v.1, p.10-43, 1911.

CAPUTO, H. P. Mecânica dos solos e suas aplicações. 6 ed. Rio de Janeiro: LTC Editora S.A, 1994, 225p.

CAPUTO, H.P. Mecânica dos Solos e suas aplicações: Fundamentos. 6 ed. Rio de Janeiro: LTC Editora S.A, 1988, 234p.

CANILLAS, E.C.; SALOKHE, V.M.A decision support system for compaction assessment in agricultural soils. Soil and Tillage Research, v.65, n.2, p.221-230, maio, 2002.

DIAS JUNIOR, M.S.; PIERCE, F.J. O processo de compactação do solo e sua modelagem. Revista Brasileira de Ciência do Solo, v.20, n.2, p.175182, 1996.

DIAS JUNIOR, M.S.; ESTANISLAU, W.T. Grau de compactação e retenção de água de latossolos submetidos a diferentes sistemas de manejo. Revista Brasileira de Ciência do Solo, v. 23, p.45-51, 1999.

EMPRESA BRASILEIRA DE PESQUISA AGROPECUÁRIA - EMBRAPA. Manual de métodos de análise de solo. 2. ed. Rio de Janeiro: Centro Nacional de Pesquisa de Solos. 1997, 212p.

FIGUEIREDO, L.H.A.; DIAS JÚNIOR, M. S.; FERREIRA, M.M. Umidade crítica de compactação e densidade do solo máxima em resposta a sistemas de manejo num Latossolo Roxo. Revista Brasileira de Ciência do Solo, v.24, n.3, p.487-493, 2000. 
GUPTA, S.C.; ALLMARAS, R. R. Models to access the susceptibility of soil to excessive compaction. Advances in Soil Sciences, New York, v.6, p.65-100, 1987.

INPE. Instituto Nacional de Pesquisas Espaciais. Sistema Nacional de Dados Ambientais: SINDA. Disponível em: <http://sinda.crn2.inpe.br/PCD/ metadados.jsp uf $=8 \& \mathrm{id}=32360 \&$ tipo $=$ MET $>$. Acesso em 7 de Out 2011.

KIEHL, E.J. Manual de Edafologia - Relações Solo-Planta. Edição. São Paulo: Editora Agronômica Ceres, 1979, 264p.

OLIVEIRA, G.C.; DIAS JUNIOR, M.S.; RESCK, D.V.S.; CURI, N. Alterações estruturais e comportamento compressivo de um Latossolo Vermelho Distrófico argiloso sob diferentes sistemas de uso e manejo. Pesquisa Agropecuaria Brasileira, v.38, n.2, p.47-50, Fev. 2003.

SAEG: Sistema para Análises Estatísticas, versão 9.1. Viçosa: UFV, 2007.

SEWELL, J.I.; MOTE, C.R. Liquid-limit determination for indicating effectiveness of chemicals in pond sealing. Transaction of the ASAE, St. Joseph. v.12, n.5, p.611-613, sept./oct. 1969.

SILVA, A. J. N.; CABEDA, M. S. V.; CARVALHO, F. G. Matéria orgânica e propriedades físicas de um Argissolo Amarelo Coeso sob sistemas de manejo com cana-de-açúcar. Revista Brasileira de Engenharia Agrícola e Ambiental, v.10, n.3, p. 579-585, jan. 2006.
SILVA, R.B.; DIAS JUNIOR, M.S.; SILVA, F.A. M.; FOLE, S. M. O tráfego de máquinas agrícolas e as propriedades físicas, hídricas e mecânicas de um Latossolo dos Cerrados. Revista Brasileira de Ciência do Solo, Viçosa, v.27, n.6, p.973-983, nov./dec. 2003.

SILVA, V.R.; REINERT, D.J.; REICHERT, J.M. Suscetibilidade à compactação de um Latossolo Vermelho- Escuro e de um Podzólico VermelhoAmarelo. Revista Brasileira de Ciência do Solo, Viçosa, v.24, n.2, p.239-249, abr./jun. 2000.

SOUZA, C. M. A.; RAFULL, L. Z. L.; VIEIRA, L. B. Determinação do limite de liquidez em dois tipos de solo, utilizando-se diferentes metodologias. Revista Brasileira de Engenharia Agrícola e Ambiental, Campina Grande, v.4, n.3, p.460-464, sept./dec. 2000.

THOMAS, G.W.; HASZLER, G.R.; BLEVINS, R. L. The effects of organic matter and tillage on maximum compactability of soils using the proctor test. Soil Science, v.61, n.3, p.502-508, ago. 1996.

TSEGAYE T.; HILL R.L. Intensive tillage effects on spatial variability of soil test, plant growth, and nutrient uptake measurements. Soil Science, v.163, n.2, p.155-165, feb. 1998.

PROCTOR, R.R. Fundamental principles of soil compaction. Engineering News Record, v.111, n.3, p. 245-248, ago./set. 1933.

VARGAS, M. Introdução à mecânica dos solos, São Paulo: Editora McGraw-Hill do Brasil, 1977, 509p. 